\title{
PESQUISA EMPÍRICA E TEORIA DO ESTADO: a experiência da avaliação legislativa da Emenda do Programa de Metas $^{1} / /$ Murilo Gaspardo²
}

\author{
Palavras-chave \\ Teoria do Estado / pesquisa empírica / avaliação \\ legislativa / emenda do Programa de Metas / \\ democracia
}

HIIIIIIIIIIIIIIIIIIIIIIIIIIIIIIIII

\section{Sumário}

1 Introdução

2 A concepção de Teoria do Estado adotada nesta investigação

3 A combinação entre teoria e empiria

4 Delimitação do problema da pesquisa: questões, planos analíticos, hipóteses, variáveis e recortes espacial e temporal

5 Método de abordagem

6 Método de procedimento: avaliação legislativa

7 Técnicas empregadas na pesquisa empírica

8 Percurso e dificuldades metodológicos

9 Conclusão

10 Referências

\section{Resumo}

Este trabalho constitui o capítulo metodológico da pesquisa "Inovação institucional e democracia participativa: avaliação legislativa da Emenda do Programa de Metas", norma aprovada em diversos municípios brasileiros e de outros países da América do Sul. A discussão metodológica em que se baseia tal investigação apresenta as seguintes indagações de fundo: como conhecer a democracia sob a ótica da Teoria do Estado? Qual a especificidade de seu enfoque? Seria possível utilizar metodologia empírica em pesquisa com esta sede epistemológica? Nossa hipótese é que a empiria confere maior objetividade à Teoria do Estado, cuja especificidade estaria em assumir como tarefa principal a projeção de instituições jurídico-políticas, não a partir de exercícios abstratos e formalistas, mas da observação da realidade, especialmente de experiências institucionais emergentes. A execução da avaliação legislativa sobre a Emenda consistiu, pois, em uma tentativa de verificação da possibilidade de adoção coerente de tal perspectiva metodológica pela Teoria do Estado. O produto deste trabalho é a descrição das premissas e do percurso metodológico da investigação sobre a Emenda: a especificação da concepção de Teoria do Estado adotada; a combinação entre teoria e empiria; a delimitação do problema da pesquisa (questões, planos analíticos, hipóteses, variáveis e recortes espacial e temporal); o método de abordagem; o método de procedimento e as técnicas empregadas; e as dificuldades metodológicas enfrentadas.

\footnotetext{
1 Este trabalho foi construído a partir das reflexões metodológicas que fundamentam a pesquisa "Inovação institucional e democracia participativa: avaliação legislativa da Emenda do Programa de Metas", financiada pela FAPESP na modalidade "Auxílio Regular" (Processo FAPESP 2015/09185 - 9). Colaboraram com a coleta bibliográfica o Professor Mauro Ferreira (PPGAPPP/UNESP) e os discentes do curso de Direito da FCHS/UNESP/Franca - SP Ana Luiza Cruz Abramovicius (Bolsista/FAPESP), Artur Marchioni (Bolsista/CNPq), Ingrid Juliane dos Santos Ferreira (Bolsista/FAPESP) e Liz Marina Tamião Santana (Bolsista/UNESP). 2 Professor de Teoria do Estado e Ciência Política no Curso de Graduação em Direito e no Programa de Pós Graduação em Direito da Faculdade de Ciências Humanas e Sociais (FCHS) da Universidade Estadual Paulista "Júlio de Mesquita Filho" (UNESP) - Campus de Franca - SP. Doutor em Direito do Estado (2013), Mestre em Direito do Estado (2009) e Bacharel em Direito (2005) pela Faculdade de Direito da Universidade de São Paulo.
} 


\section{EMPIRICAL RESEARCH AND STATE THEORY: the experience of the Target Program Amendment's legislative evaluation // Murilo Gaspardo ${ }^{3}$}

\author{
Keywords \\ State Theory / empirical research / legislative \\ evaluation / Target Program Amendment / \\ Democracy
}

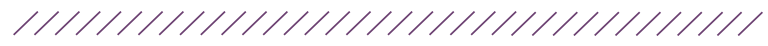

\begin{abstract}
This work constitutes the methodological chapter of the research "Institutional innovation and participatory democracy: legislative evaluation of the Target Program Amendment," a standard approved in several Brazilian cities and from other South American countries. The methodological discussion on which such research is based presents the following fundamental questions: how to understand the democracy from the point of view of State Theory? What is the specificity of its approach? Would be possible to use empirical research methodology from this epistemological locus? Our hypothesis is that the empiricism provides more objectivity to the State Theory, whose specificity would be to assume the projection of legal-political institutions as its main task, not from abstract and formalist exercises, but from the observation of the reality, especially emerging institutional experiences. The execution of the legislative evaluation about the Amendment consisted, therefore, in an attempt to verify the possibility of a coherent adoption of such methodological perspective by the State Theory. The product of this work is the description of the premises and the methodological way of the research about the Amendment: the specification of the State Theory conception adopted; the combination of theory and empiricism; the research problem delimitation (questions, analytical plans, hypotheses, variables and spatial and temporal cut-outs); the approach method; the procedure method and tools used; and the methodological difficulties that we faced.
\end{abstract}

3 Professor of State Theory and Political Science at the Law and Postgraduate Program in Law at the Faculty of Human and Social Sciences of the Universidade Estadual Paulista "Júlio de Mesquita Filho" (UNESP) - Campus de Franca - SP. Doctor of State Law (2013), Master of Law of the State (2009) and Bachelor of Law (2005) by the Faculty of Law of the Universidade de São Paulo. 


\section{Introdução}

Este trabalho insere-se em um contexto de reflexões de uma rede de pesquisadores sobre os "sentidos contemporâneos" da Teoria do Estado, e constitui o capítulo metodológico da pesquisa "Inovação institucional e democracia participativa: avaliação legislativa da Emenda do Programa de Metas".

Cinquenta e três municípios brasileiros e seis de outros países da América do Sul aprovaram Emendas às suas Leis Orgânicas que instituíram a obrigatoriedade de Prefeitos apresentarem programas de metas baseados nas propostas que defenderam durante as campanhas eleitorais, o que, associado a um conjunto de institutos complementares, possui como objetivos expressos: qualificar o debate eleitoral, contribuir com a prática do planejamento na Administração Pública e fortalecer o controle social das políticas públicas. Desenvolvemos um estudo comparativo entre os dez Municípios do Estado de São Paulo cujos Prefeitos apresentaram seu Programa de Metas para a gestão 2013 - 2016, por meio do qual pretendemos: (1) verificar se as normas estão sendo formal e materialmente cumpridas; (2) compreender as razões de seu descumprimento ou cumprimento (em diferentes graus); (3) apresentar propostas para o aperfeiçoamento de seu desenho institucional.

A discussão metodológica em que se baseia tal investigação, e que constitui o objeto específico deste trabalho, apresenta as seguintes indagações de fundo: como conhecer a democracia sob a ótica da Teoria do Estado? Qual a especificidade de seu enfoque? Nosso ponto de partida é a compreensão dessa disciplina como uma "nova ciência social", de natureza discursiva e prescritiva. Entretanto, avançamos no sentido de questionar: seria possível utilizar metodologia empírica em pesquisa com esta sede epistemológica? Ou este "conhecimento realista" deveria ser buscado apenas discursivamente?

Nosso argumento é que a empiria confere maior objetividade à Teoria do Estado, e sua especificidade estará em assumir como tarefa principal a projeção de instituições jurídico-políticas, não a partir de exercícios abstratos e formalistas, mas da observação da realidade, especialmente de experiências institucionais emergentes (Boaventura de Sousa Santos,
2012), bem como em exercícios de mapeamento e experimentalismo democrático (Unger, 1996). Essa perspectiva, por um lado, exige rigor técnico; mas, por outro, é eminentemente política: a interpretação da realidade depende dos critérios adotados (que, neste campo, necessariamente apresentam um componente axiológico); e as prescrições envolvem opções entre interesses conflitantes e um engajamento no sentido de transformação (ou conservação) não só das instituições, mas também da sociedade na qual estão inseridas.

A execução da avaliação legislativa sobre a Emenda consistiu, pois, em uma tentativa de verificação da possibilidade de adoção coerente de tal perspectiva metodológica pela Teoria do Estado. Neste trabalho descrevemos as premissas e o percurso metodológico de tal investigação.

\section{A concepção de Teoria do Estado adotada nesta investigação}

A Teoria do Estado é uma disciplina na qual não são comuns trabalhos de natureza empírica, pelo menos na concepção que empregamos. Embora seja notável o avanço da pesquisa empírica em Direito no Brasil, com a ampliação do diálogo com outras ciências sociais e abrangendo diferentes ramos (Direito Constitucional, Direito Processual, Direito Penal, Criminologia, Direito do Trabalho etc.), em perspectivas diversas, ela apresenta maior desenvolvimento nos campos do sistema judiciário em sentido amplo (Poder Judiciário, Ministério Público, Defensoria Pública, polícias, sistema prisional etc.) e dos movimentos sociais, sendo ainda incipientes no âmbito da Teoria do Estado e na análise de instituições democráticas. Além disso (e mais importante), ao longo de sua evolução histórica, a Teoria do Estado tem sido marcada por uma permanente disputa quanto a seus paradigmas metodológicos e conceituais, situação esta que se agravou com o processo de globalização.

A polêmica a propósito da definição do método e do objeto da Teoria do Estado está presente desde os primórdios da disciplina, no final do século XIX, e se desenvolve no século XX. O Estado deveria ser compreendido exclusivamente como "realidade normativa" (formalismo jurídico, tal como defendia Kelsen)? 
Ou então, seria mais adequada uma perspectiva "eminentemente realista, dando absoluta preponderância aos fatos concretos" (próxima a uma Sociologia do Estado, da maneira proposta por Heller)? Ou ainda, a especificidade da Teoria do Estado estaria na pretensão de realizar uma "síntese dinâmica" das perspectivas filosófica, normativista e realista (culturalismo realista proposto por Reale)? (Dallari, 2010, p. 6 - 7).

Nos anos 90, Tojal (1997) apontou que se estava diante de uma "crise de degenerescência dos paradigmas epistemológicos da Teoria Geral do Estado", e defendeu que a disciplina deveria ser compreendida como uma nova Ciência Social, a qual, sem abandonar sua fundamental dimensão normativa, deve realizar uma pesquisa interdisciplinar sobre os objetos propostos, considerando sua dinâmica social, mas não de caráter empírico, e sim discursivo. Também não se deveria idealizar axiologicamente o Estado, nem pretender uma neutralidade impossível diante de um objeto de natureza cultural, tendo em vista a produção de um conhecimento realista e transformador.

Assinalamos, todavia que, diferentemente da proposta de Tojal (1997), entendemos que a Teoria do Estado deve ser compreendida como uma nova ciência social que também se vale de metodologia empírica na observação de seus objetos de estudo. Entretanto, na compreensão de seus objetos e na elaboração de suas prescrições (ou em seu enfoque de arquitetura institucional), a disciplina conserva um caráter eminentemente discursivo.

Assim, em primeiro lugar, a dimensão normativa é fundamental na pesquisa, pois, por um lado, seu objeto é uma norma jurídica, ainda que não estudada de forma predominantemente dogmática; e, por outro, a quarta etapa da pesquisa assume um caráter prescritivo (portanto, normativo). Em segundo lugar, seu objeto não é abordado de uma perspectiva jurídico-formal, mas interdisciplinar, em especial diálogo com a Ciência Política. Consequentemente, a instituição jurídico-política é analisada em sua dinâmica social - trata-se da busca de um conhecimento da realidade, não idealizado. Entretanto, o fato de se tratar de um conhecimento não idealizado não significa que seja neutro (Boaventura de Sousa Santos, 2001). Trata-se de uma perspectiva que se aproxima de uma
Teoria Política normativa aplicada, ou seja, orientada para a elaboração de proposições normativas com o objetivo de resolver problemas concretos, fundada não apenas em valores abstratos mas também na observação do contexto empírico em que serão aplicadas. Tais proposições não consistem em orientações de dever-ser para a conduta dos indivíduos, mas em projetos de construção ou reforma de instituições (Bauböck, 2008) - no caso da Teoria do Estado, especificamente instituições jurídicas.

A natureza do Estado enquanto objeto de pesquisa possibilita um conhecimento razoavelmente objetivo - com rigorosa e metódica observação da realidade, mas não neutro. Ora, nas ciências humanas, o que se faz não é apenas explicar a realidade, mas também compreendê-la. A compreensão do comportamento humano envolve o sentido que lhe é atribuído pelo pesquisador e também "o sentido que ele próprio se dá", de maneira que o valor the é um elemento inerente $^{4}$ (Ferraz Jr., 1980). Além disso, como ressalta Tojal (1997, pp. 158 - 159), o Estado é um objeto historicamente concreto, do qual "seu investigador é integrante e atuante”. A pretensão de neutralidade, imparcialidade e universalidade é em si ideológica, pois os conhecimentos abstratos que se busca produzir com essas características são, na verdade, frutos de valores particulares socializados pela força, por exemplo, de um modelo econômico. É melhor, portanto, explicitar qual o interesse e qual a ideologia que orientam determinada investigação científica, de forma que os interlocutores possam avaliar como influenciam o conhecimento produzido.

Aplicando-se essa perspectiva ao objeto desta pesquisa, ressaltamos que desenvolvemos um esforço para observar objetivamente a realidade, a fim de aferir, sem idealizações, se a Emenda está sendo cumprida, se os objetivos pretendidos quando de sua edição estão sendo atingidos ou não, e por quais razões. Para tanto, utilizamos rigorosos processos de coleta e análise de dados diversificados, e testamos criticamente nossas hipóteses, considerando as diferentes

4 Cf. a classificação sobre as diferentes perspectivas epistemológicas desenvolvidas por Marsh e Furlong (2002), que as dividem em positivista, hermenêutica, realista e construtivista, com seus diferentes fundamentos ontológicos. 
variáveis relevantes. Entretanto, se é possível aferir com alto grau de objetividade se a norma está sendo cumprida formalmente, o mesmo não ocorre no que se refere à verificação do êxito de seus objetivos de uma perspectiva substancial, na qual o elemento interpretativo é fundamental, com influência inevitável dos valores do pesquisador. Até porque, a própria escolha dos parâmetros (o modelo de democracia participativa enquanto projeto de emancipação social e a experiência prévia do pesquisador como autor - na condição de legislador municipal - de uma das Emendas avaliadas) não é neutra. 0 mesmo podemos afirmar quanto à análise das razões para o êxito ou fracasso dos objetivos pretendidos com a inovação institucional em questão - por mais que se busque objetividade na consideração de seus diferentes fatores relevantes, a neutralidade é impossível, pois é influenciada pela concepção do pesquisador sobre os processos políticos, construída a partir de seus referenciais teóricos e do contexto no qual está inserido. Finalmente, embora as propostas de alteração legislativa que constituem o produto final da investigação tenham como pressuposto uma avaliação empírica sobre a aplicação da Emenda, toda proposta tem uma finalidade, e nos fins estão embutidos valores. Assim, desde o princípio, esclarecemos que adotamos como parâmetro axiológico uma perspectiva contra-hegemônica de democracia.

Além de realista, espera-se que o conhecimento a ser produzido seja transformador, no sentido de gerar uma melhor compreensão sobre a aplicação da Emenda, bem como propostas de aperfeiçoamento institucional que possam impactar na realidade - e diante deste propósito transformador não é possível estabelecer uma separação rígida entre sujeito e objeto da pesquisa. Dessa maneira, no que se refere ao enfoque adotado, entendemos que a principal contribuição que a Teoria do Estado tem a oferecer para o estudo sobre os problemas contemporâneos da democracia consiste em, a partir de resultados de estudos empíricos sobre as instituições democráticas e de modelos teóricos contemporâneos de democracia, identificar alternativas de desenhos institucionais emergentes e desenvolver propostas de engenharia jurídico-institucional (Boaventura de Sousa Santos, 2011). Em última análise, esta é a motivação desta pesquisa: conhecer o potencial da Emenda do Programa de Metas enquanto inovação institucional no campo da democracia e avaliar as possibilidades de seu aperfeiçoamento e de sua expansão.

Observamos, por fim, que o reconhecimento da importância das regras de inferência e demais cânones metodológicos da pesquisa empírica para a validade dos resultados da pesquisa científica (inclusive desta), não significa que o modelo de racionalidade da ciência moderna, originado nas ciências naturais, seja tomado de forma acrítica. Como já observava Boaventura de Sousa Santos (1988) há quase três décadas, há limites ao denominado "rigor científico". Por exemplo, ao contrário do que pretende tal paradigma: a racionalidade e o conhecimento válido não são exclusivos da ciência moderna (a ciência deve dialogar com outras formas de conhecimento); o conhecimento não pode ser reduzido à possibilidade de quantificação e medição; e não é possível a separação radical entre sujeito (que conhece) e objeto. Além disso, as consequências do conhecimento produzido não são irrelevantes, daí o autor se referir à emergência do "paradigma de um conhecimento prudente para uma vida decente".

\section{A combinação entre teoria e empiria}

De maneira bastante sintética, uma pesquisa empírica pode ser definida como aquela que produz conhecimento por meio da "observação do mundo" (ou de experiências), baseada em dados, a qual pode apresentar um caráter quantitativo ou qualitativo (Epstein \& King, 2013, p. 11). As disciplinas dessa natureza diferenciam-se das filosóficas porque sua preocupação se volta para "a maneira como as coisas funcionam e não como elas devem funcionar, e resolvem suas questões empiricamente" (Becker, 2014, p. 186). Todavia, não se trata simplesmente de uma coleta e sistematização de dados sobre determinado objeto de investigação - isso teria pouca utilidade para a compreensão da realidade bem como para fornecer elementos para a intervenção sobre ela - ou seja, tratar-se-ia de uma pesquisa com diminuta relevância teórica e prática. Em última análise, não há ciência sem teoria. Como assevera Popper (2008, p. 114), "uma ciência requer pontos de vista e problemas teóricos". Mas o que se entende por teoria?

Mais uma vez na lição de Popper (2008, p. 61), as teorias podem ser compreendidas como "redes, 
lançadas para capturar aquilo que denominamos 'o mundo’: para racionalizá-lo, explicá-lo, dominá-lo”. As teorias, portanto, desempenham um papel central na pesquisa científica. Como explica o referido autor (2008, p. 27), a tarefa do cientista, teórico ou empírico, é formular "enunciados ou sistemas de enunciados" (teorias) e verificá-los. Mais precisamente, nas ciências empíricas, "ele formula hipóteses ou sistemas de teorias, e submete-os a teste, confrontando-os com a experiência, através de recursos de observação e experimentação". (Popper, 2008, p. 74).

Valverde (2016, pp. 173 - 174) também entende que os acadêmicos que desenvolvem pesquisas empíricas precisam de "theoretical inspiration and theoretical tools to put their particular research into a broader contest". Porém, de acordo com a autora, nem a Filosofia do Direito nem as grandes teorias da Sociologia do Direito europeias - as quais considera as principais referências de teorias jurídicas disponíveis no Ocidente, especialmente nos países que adotam o modelo da "civil law" - são úteis para fornecer as referências e as ferramentas para a realização de pesquisas empíricas em direito contemporaneamente. Ao contrário, muitas vezes criam obstáculos para tanto. Isso ocorre porque tais teorias têm a pretensão de fornecer sistemas de explicação globais para os fenômenos em um contexto em que o pluralismo jurídico se torna a regra. Além disso, há variadas e relevantes experiências e construções intelectuais em diversas partes do mundo que são ignoradas pelos modelos teóricos eurocêntricos. Por outro lado, a autora defende que há outros recursos teóricos e metodológicos emergentes que podem ser uma alternativa para esse problema. Essas teorias caracterizam-se pela diversidade, pela ausência de pretensões de grandiosidade e de explicações totalizantes, pelo fomento ao trabalho coletivo e por se voltarem para explicações de fenômenos mais particulares.

A referência até aqui é a teoria explicativa. Todavia, a proposta desta pesquisa consistiu não apenas em verificar teorias explicativas, mas também em desenvolver prescrições (teoria normativa) a partir da pesquisa empírica.

Adotamos o modelo de democracia participativa como referência teórica, o qual apresenta tanto uma vertente explicativa, enquanto descrição de determinadas experiências políticas, como uma prescritiva, ao indicar um dever-ser para as instituições democráticas alternativo ao modelo hegemônico liberal-elitista. Tal modelo não foi construído simplesmente a partir de formulações abstratas, mas da observação de experiências de inovações institucionais de diversas partes do mundo, como o orçamento participativo, originado no Brasil e aplicado em diversos países. Tanto as experiências como as construções teóricas relacionadas à democracia participativa, em boa medida, enquadram-se na proposta defendida por Valverde. Em primeiro lugar, porque não são eurocêntricas; pelo contrário, boa parte de seus fundamentos origina-se no Sul Global geopolítico. Além disso, não obstante seja uma proposta abrangente, constrói-se a partir da riqueza da diversidade de experiências.

Assim, a democracia participativa fornece os parâmetros interpretativos para os dados levantados na observação da aplicação da Emenda do Programa de Metas e valores que orientam as propostas de aperfeiçoamento do instituto. Tais parâmetros indicam a insuficiência das instituições representativas para a realização de princípios e valores da democracia, bem como a possibilidade de construção de inovações institucionais de caráter participativo com respostas mais satisfatórias. Por outro lado, de certa forma, o modelo de democracia participativa foi testado no desenvolvimento desta investigação. Evidentemente, em uma pesquisa circunscrita como esta, não tivemos a pretensão de obter confirmações definitivas para seus postulados (o que nem deve ser considerada uma possibilidade na ciência), uma refutação ou uma proposta de modificação estrutural e, muito menos, a formulação de uma nova teoria. Entretanto, há implicações da empiria sobre a teoria.

É importante ponderar, por fim, que as ciências empíricas têm a pretensão de explicar como as coisas funcionam e não como devem funcionar. Entretanto, como esclarecemos na seção anterior, a concepção da Teoria do Estado adotada não desloca completamente essa ciência, em sua origem normativa, para o campo das ciências empíricas.

De fato, entendemos que a Teoria do Estado deve ser realista, basear-se na observação do mundo, cons- 
truindo explicações fundadas, em parte, na empiria em sentido estrito, bem como em uma prática discursiva, pois seu objeto não permite que se proceda de forma diferente. Porém, a Teoria do Estado conserva sua dimensão normativa, tanto pela centralidade do elemento jurídico na constituição de seu objeto, enquanto fator de institucionalização das relações políticas, como em seu enfoque de projeção de instituições, baseado, é verdade, em experiências em curso (ou, na expressão de Boaventura de Sousa Santos, em uma "sociologia das emergências"), mas também em valores e interesses inerentes ao pesquisador e ao espaço geopolítico e social que ocupa.

\section{Delimitação do problema da pesquisa: questões, planos analíticos, hipóteses, variáveis e recortes espacial e temporal}

$\mathrm{Na}$ definição do objeto desta pesquisa, procuramos seguir a recomendação de Epstein e King (2013, pp. 72 - 78) sobre seus dois requisitos fundamentais: por um lado, deve contribuir com o avanço do "conhecimento existente", ou seja, com a literatura acadêmica, integrando-se ao "empreendimento social" de construção do conhecimento; por outro lado, deve ter relevância para o "mundo real”.

O campo temático da democracia participativa e do controle social é objeto de grande produção acadêmica desde, pelo menos, os anos setenta do século $X X$, e continua a ser explorado a partir de diferentes perspectivas. Particularmente a experiência da Emenda do Programa de Metas, embora ainda seja pouco estudada, já se apresenta como objeto de pesquisas, sobretudo no âmbito da Administração Pública, muitas das quais desenvolvidas por sujeitos que, além de pesquisarem o tema, atuaram em sua formulação e aplicação. Portanto, somamo-nos a um esforço coletivo de construção do conhecimento sobre a temática. Já a importância desta investigação para o "mundo real" evidencia-se no fato de se voltar para a análise do "direito em ação" - a forma como a Emenda está sendo aplicada, em um contexto de grande demanda social por reformulações na institucionalidade da democracia e da Administração Pública.

De maneira bastante sintética, o problema desta pesquisa pode ser resumido em três perguntas: a) a Emenda do Programa de Metas está atingindo os objetivos pretendidos? b) por quais razões? c) como esta inovação institucional pode ser aperfeiçoada?

Embora tais perguntas constituam o objeto imediato desta pesquisa, há algumas questões de base sobre as quais elas se apoiam e, respondendo-se às primeiras, talvez seja possível inferir alguns elementos para enfrentar as últimas (não obter respostas conclusivas). Tais questões encontram-se no horizonte desta investigação e são as seguintes: a) se as instituições representativas vigentes revelam-se insuficientes (ou inadequadas) para a mediação dos conflitos na complexa sociedade contemporânea, quais alternativas se apresentam? Quais tendências podem ser percebidas? Há inovações institucionais em curso que possam ser amplificadas? b) qual o papel e quais os limites da influência das instituições jurídicas no processo político-democrático? Como os elementos institucionais se relacionam com outros fatores?

Desenvolvemos esta pesquisa em quatro planos analíticos conectados e sucessivos. Primeiramente, em uma investigação de caráter descritivo, verificamos se as normas previstas nas emendas às Leis Orgânicas estão sendo formalmente cumpridas, levando em conta seus elementos estruturantes. Sabe-se, todavia, que o fato de uma lei ser formalmente cumprida não assegura que os objetivos pretendidos com a sua edição sejam efetivamente atingidos. Assim, ainda no plano descritivo, investigamos se as normas estão sendo materialmente cumpridas, ou seja, se estão sendo atingidos os objetivos explicitamente declarados (tanto em suas "exposições de motivos" como nos debates que antecederam sua aprovação). Em terceiro lugar, adotando um plano de análise explicativo, investigamos as razões do descumprimento ou do cumprimento (em diferentes graus) da norma, tanto em termos formais como materiais, bem como da possível produção de efeitos não esperados, mediante um estudo comparativo de caráter exploratório (Gil, 2008) entre diferentes municípios. Finalmente, a partir das conclusões obtidas nas três etapas que exploraram o objeto do estudo mediante análises descritivas e explicativas (integradas por meio da comparação entre os diferentes casos estudados), na quarta e última etapa, adotamos um enfoque prescritivo para apresentar propostas de alteração legisla- 
tiva que possam contribuir com o êxito da Emenda do Programa de Metas no cumprimento de seus objetivos, bem como com o aperfeiçoamento do Projeto de Emenda Constitucional referente à matéria que se encontra em tramitação no Congresso Nacional.

A divisão da pesquisa nesses diferentes planos analíticos permitiu demarcar no desenvolvimento da análise a gradação da relação estabelecida entre sujeito e objeto: da maior objetividade analítica no primeiro plano, passamos por dois intermediários com maior carga interpretativa e valorativa, até um maior grau de envolvimento na etapa prescritiva. A clareza desta demarcação é fundamental para a crítica dos resultados por outros pesquisadores. Formuladas as perguntas da investigação, passamos à formulação das hipóteses.

Como essa pesquisa envolveu diferentes planos analíticos com características específicas, optamos por adotar posturas distintas em relação à formulação de hipóteses para cada um deles. Com relação à verificação do cumprimento formal das normas previstas na Emenda, entendemos que não haveria utilidade na formulação de uma hipótese do tipo "é cumprida” ou "não é cumprida", de maneira que preferimos passar das perguntas à busca de evidências. Já no que se refere à aferição do cumprimento material das normas e às razões que explicam determinado resultado, a formulação de hipóteses contribuiu com o desenvolvimento da pesquisa. Por fim, no plano prescritivo entendemos que não seria possível nem teria sentido a formulação de hipóteses, visto que as prescrições a serem formuladas teriam como pressuposto a verificação das hipóteses dos planos descritivo e explicativo.

As hipóteses formuladas para os problemas desta pesquisa tiveram diferentes fontes: a) revisão da literatura selecionada sobre democracia participativa, inovação institucional e as condições históricas de exercício da cidadania no Brasil; b) revisão da literatura existente sobre a Emenda; c) estudo exploratório preliminar de mapeamento legislativo; d) entrevistas não-estruturadas com informantes com grande conhecimento sobre o objeto da pesquisa; e) nossa experiência pessoal com o objeto da investigação.

A explicação para diferentes graus de êxito (ou fracasso) da Emenda no que se refere ao incremento do controle social das políticas públicas e ao aperfeiçoamento da democracia não foi procurada apenas no elemento jurídico (vigência e conteúdo da norma), mas também em fatores sociais (como a existência de movimentos semelhantes à "Rede Nossa São Paulo" - RNSP - e a atuação de outros movimentos sociais), culturais e políticos (como o perfil do prefeito e o conjunto de forças políticas de cada município). Após a definição das hipóteses, passamos à determinação das variáveis a serem medidas.

Quando consideramos o problema do cumprimento material da Emenda, há duas possibilidades extremas de resposta (sim ou não) e um amplo intervalo (cumprimento parcial) que, se não pode ser quantificado, deve ser qualificado. Nesse plano analítico, em princípio, duas variáveis foram consideradas: a própria Emenda (variável independente) e os objetivos estabelecidos quando da edição da norma (conjunto de variáveis dependentes). Porém, não poderíamos desprezar a possibilidade de, em determinado município em que a Emenda foi editada, observarmos a concretização de objetivos semelhantes aos nela estabelecidos, sem que a causa efetiva seja a norma, mas, por exemplo, movimentos sociais que pressionam o Governo. Assim, tais movimentos foram considerados uma variável de moderação quando apuramos que a Emenda está atingindo seus propósitos.

No que se refere ao plano analítico explicativo, a composição das variáveis foi mais complexa. A variável independente, novamente, foi a norma, mas considerada de outra perspectiva: o que nos interessava saber é se o texto normativo seria o fator que explica o êxito ou o fracasso (variável dependente) dos objetivos pretendidos com a sua edição. Mais uma vez, como variável de moderação, consideramos a existência (ou não) de movimentos sociais (como a RNSP e outros semelhantes) que acompanham o cumprimento da Emenda. Verificar a relação entre essas variáveis foi fundamental até porque, em alguns casos, a existência ou ausência de movimentos sociais capazes de realizar um monitoramento eficaz revelou-se como uma variável tão ou mais importante do que a própria norma. Assim, em princípio, trabalharíamos com duas categorias de municípios dentro do universo desta investigação: a) os que apresentam a Emenda, mas não movimentos organizados que acompanham seu cumprimento; e b) os 
que apresentam tanto a Emenda como movimentos. Entretanto, para aferirmos qual seria, de fato, o peso da variável de moderação, julgamos importante considerar uma terceira categoria de municípios: aqueles nos quais, embora não exista uma Emenda à Lei Orgânica do Programa de Metas, há movimentos sociais empenhados por objetivos semelhantes aos nela previstos. Outras variáveis de moderação, embora com peso menor, também se mostraram relevantes, como o perfil do prefeito e a composição das forças políticas do município. Por fim, julgamos ser imprescindível considerar as condições histórico-sociais de exercício da cidadania no Brasil, presentes em todos os municípios (com especificidades, evidentemente). Essas condições foram tratadas como variáveis de controle.

Identificadas as variáveis da investigação, passamos a uma nova etapa do delineamento de uma pesquisa empírica: como medir as variáveis e obter estimativas? A avaliação das hipóteses exige que as variáveis sejam "traduzidas" em indicadores precisos, que permitam comparações (Epstein \& King, 2013, pp. 100 - 102).

A medida, evidentemente, reduz a realidade observada aos critérios por ela estabelecidos, não permitindo a compreensão da complexidade do todo, porém, "a medida nos permite colocar na mesma dimensão eventos ou assuntos aparentemente discrepantes, tornando muito mais fácil compreender pelo menos um aspecto do fenômeno em estudo". A questão é estabelecer medidas que sejam capazes de permitir a captação de "todas as partes que são essenciais à questão da pesquisa”. E essa regra vale igualmente para "uma pesquisa empírico-quantitativa e para trabalhos qualitativos". Nas quantitativas, são atribuídos valores numéricos às medidas. Já nas qualitativas são utilizadas categorizações, que devem ser suficientemente definidas, de maneira que possam ser aplicadas "de forma não ambígua" - ou seja, "é preciso definir o padrão para a categorização ou medida" (Epstein \& King, 2013, pp. 103 - 105).

A estimativa, por sua vez, é "uma medida em escala maior", reflete a média das medidas sobre unidades de observação específicas. Para se aferir a qualidade de uma estimativa, utiliza-se como critérios a imparcialidade, a eficiência e a consistência (Epstein \& King, 2013, pp. 123 - 126).
A aplicação dessas regras ao objeto desta investigação não pode ser considerado algo simples. Não foi difícil quantificar os dispositivos legais da Emenda que foram cumpridos e por quantos municípios analisados. Entretanto, medir e estimar o aperfeiçoamento do controle social das políticas públicas obtidos em razão da Emenda, bem como as explicações para seu êxito ou fracasso nas diferentes localidades analisadas constituiu tarefa bastante complexa. Quais indicadores poderiam fornecer essas medidas e estimativas? Quais categorias qualitativas poderíamos utilizar? Não obstante essas dificuldades, procuramos construir categorias de medidas ao resumirmos os dados coletados tomando todo o cuidado para assegurar sua confiabilidade e validade, deixando claros e transparentes os critérios utilizados em sua formulação, e adotando as regras da validade visual, da imparcialidade e da eficiência - com a ressalva de que aproximamos a ideia de imparcialidade de objetividade, não de neutralidade, conforme já exposto. No que se refere à estimativa sobre a Emenda podemos dizer que, de certa forma, ela corresponde à média das medidas obtidas na observação de cada um dos municípios estudados. Combinamos, assim, uma preocupação com o rigor formal na definição de procedimentos de pesquisa, categorias e ferramentas para a análise dos dados, com uma explícita perspectiva crítica assentada na compreensão da democracia como projeto de emancipação social (e não como mera forma política) e em nossa experiência e "lugar" sociopolítico como sujeito da investigação.

A população de interesse desta pesquisa - ou seja, o universo a ser observado para coletar os dados necessários para responder ao problema formulado corresponde a todos os municípios brasileiros e da América do Sul em que foram editadas as Emendas, bem como aqueles em que, embora não disponham da referida norma, apresentam movimentos semelhantes à RNSP. Definimos essa população de interesse a partir das informações disponíveis no portal da RNSP e coletamos todas as Emendas e links de portais de movimentos semelhantes à RNSP.

Entretanto, por razões operacionais, inicialmente, circunscrevemos o universo a ser observado ao âmbito do Estado de São Paulo, e verificamos, dentre os municípios com a Emenda editada, em quais de- 
les o Prefeito apresentou seu Programa de Metas. Em relação àqueles nos quais o Programa sequer foi apresentado formalmente, há forte evidência de que a norma não apresenta nenhuma efetividade e seus objetivos não estão sendo atingidos, de maneira que não haveria razões para priorizar a realização de um estudo mais aprofundado sobre eles, tendo em vista os limites temporais e estruturais existentes para a realização desta investigação. Assim, limitamos o recorte espacial aos Municípios do Estado de São Paulo cujos Prefeitos apresentaram seu Programa de Metas para a gestão 2013 - 2016: Bragança Paulista, Campinas, Holambra, Jaboticabal, Jundiaí, Louveira, Mirassol, São Carlos, São José do Rio Preto e São Paulo. Para efeitos de controle, como exposto anteriormente, julgamos necessário analisar municípios onde não foram aprovadas Emendas, mas há movimentos sociais que acompanham os indicadores locais da gestão pública, inspirados na RNSP, o qual impulsionou a experiência pioneira do Município de São Paulo. Em razão de seu nível de organização e mobilização (indicado pela própria RNSP), com relação a esses municípios, restringimos a amostra a Piracicaba e Mogi das Cruzes.

Em termos temporais, no que se refere à gênese das Emendas, interessou-nos coletar dados (em perspectiva exploratória) desde o momento em que os projetos foram apresentados (e as circunstâncias nas quais isso ocorreu). Todavia, para que os casos (municípios) estudados pudessem ser adequadamente comparados, a avaliação da aplicação das normas limitou-se aos mandatos dos prefeitos eleitos em 2012, mais precisamente, entre $1^{\circ}$ de janeiro de 2013 de 31 de dezembro de 2016.

\section{$5 \quad$ Método de abordagem}

Após a delimitação do problema desta pesquisa, devemos indicar e justificar o método de abordagem utilizado em seu desenvolvimento, considerando-se qual se revelou mais adequado para o objeto proposto. Porém, como a pesquisa se desenvolveu em diferentes planos analíticos, foi necessária a adoção de diferentes métodos.

Como já indicamos, no primeiro plano analítico (descritivo) - no qual verificamos o cumprimento formal da Emenda - não formulamos hipóteses previamente à execução e utilizamos o método indutivo: a partir da observação de casos particulares procuramos obter uma generalização (a Emenda é ou não formalmente eficaz?). Por sua vez, no último plano analítico (prescritivo), a partir das evidências empíricas e das referências teóricas (com o conteúdo valorativo que lhes é inerente), discursivamente apresentamos propostas de alteração legislativa tendo em vista o aperfeiçoamento da Emenda, em um exercício tecnológico, de arquitetura institucional. Foram mais complexas e exigem maiores esclarecimentos as escolhas metodológicas do segundo (também descritivo) e do terceiro (explicativo - exploratório) planos analíticos, respectivamente, destinados a verificar se a norma está atingindo seus objetivos do ponto de vista substancial e por quais razões. Para ambos, como já se pôde depreender da apresentação do problema, adotamos orientações gerais do método hipotético-dedutivo, devidamente ajustadas, por se tratar de uma pesquisa empírica de natureza social e qualitativa.

Como se sabe, o método hipotético-dedutivo foi proposto por Popper, em obra publicada originalmente em 1935, a partir de suas críticas ao método indutivo. Nas palavras de Popper (2008, p. 34), “uma decisão positiva só pode proporcionar alicerce temporário à teoria, pois subsequentes decisões negativas sempre poderão constituir-se em motivo para rejeitá-la". Consequentemente, o que se pode afirmar sobre uma teoria que "resista a provas pormenorizadas e severas, que não seja suplantada por outra, no curso do progresso científico" é que ela foi "corroborada pela experiência passada" (Popper, 2008, p. 34). Assim, para Popper (2008, p. 42) o reconhecimento de um sistema (teoria) como empírico ou científico não depende de sua capacidade de se mostrar absolutamente válido, mas sim "que sua forma lógica seja tal que se torne possível validá-lo através de recurso a provas empíricas, em sentido negativo: deve ser possível refutar, pela experiência, um sistema científico empírico". A partir dessas premissas, Popper (2008, p. 56) prescreve que a "regra suprema" do processo científico é que todas as suas regras "devem ser elaboradas de maneira a não proteger contra o falseamento qualquer enunciado científico". Consequência lógica disso é que "todo enunciado científico permaneça provisório para sempre” (Popper, 2008, p. 308). 
Esses pressupostos foram seguidos no tratamento das hipóteses descritivas e explicativas, de maneira que: a) com fundamento na pesquisa bibliográfica, na observação exploratória preliminar e em nossas experiências, elaboramos nossas hipóteses provisórias de respostas ao problema da investigação; b) submetemos essas hipóteses a críticas, a procedimentos de falseabilidade, por meio do método de procedimento da avaliação legislativa; c) então chegamos à nossa conclusão (sempre provisória) e foram gerados novos problemas de pesquisa.

Todavia, como já afirmamos, essas orientações do método hipotético-dedutivo devem ser ajustadas por se tratar de uma pesquisa de natureza social e qualitativa. Uma das razões para isso é que o valor da contribuição desta investigação não se limita à oposição absoluta confirmação ou rejeição da hipótese, pois abrange suas minúcias, os detalhes, enfim, as diferentes qualificações do fenômeno observado: tão (ou mais) importante (cientificamente) e útil (socialmente) que a resposta para o problema pesquisado é sua fundamentação. Neste ponto, a perspectiva interpretativa, a compreensão do fenômeno estudado (êxito ou fracasso dos propósitos que motivaram a edição da Emenda e suas razões) ganham relevo, com suas implicações para a influência dos valores nas conclusões do pesquisador.

Outra diferença importante da pesquisa qualitativa que realizamos em relação aos cânones do método hipotético-dedutivo é que, embora tenhamos estabelecido nosso objeto, nossas perguntas e variáveis antes do início da investigação, isso não ocorreu exclusivamente por meio da revisão bibliográfica, mas incluiu o início da atividade de campo, por exemplo, com observações e a realização de entrevistas não estruturadas com informantes conhecedores da Emenda, bem como nossa experiência política com o objeto. Além disso, perguntas e variáveis estabelecidas inicialmente passaram por processos de reformulação com o progresso do trabalho de coleta e análise de dados; o próprio objeto ganhou maior especificidade e as explicações provisórias se consolidam gradativamente (Deslauriers \& Kérsit, 2010, p. 137).

Não obstante consideremos importantes as orientações gerais do método hipotético-dedutivo apresen- tadas, a opção pelo caráter qualitativo desta pesquisa não foi casual - ela decorreu da natureza do objeto e dos problemas formulados. Como avaliamos os resultados de uma instituição jurídico-política, o método qualitativo se mostrou o mais adequado para um conhecimento abrangente de seus "efeitos concretos" e de todos os aspectos do fenômeno. Além disso, lidamos com dados de difícil mensuração, mas que têm muito a dizer sobre mecanismos e atores envolvidos no processo de concretização da norma ("o ‘como' e o ‘o que' dos fenômenos”) (Deslauriers \& Kérsit, 2010, pp. 130 - 132).

Essa escolha da perspectiva qualitativa não significa que questões quantitativas foram ignoradas, embora o recurso àquela perspectiva enfrente severas limitações para o conhecimento de nosso objeto. Dados numéricos foram considerados na análise desenvolvida, tais como a quantidade de municípios em que o Prefeito apresentou seu Programa de Metas dentro do prazo previsto e o número de audiências públicas realizadas para debater o Programa e o de participantes, dentre outros. Combinamos, pois, a maior quantidade possível de dados e de diversas naturezas na tentativa de responder às questões que formulamos.

Não tivemos a pretensão de abranger todos os elementos existentes que indicam o grau de efetividade da norma, nem as razões que os explicam, até porque, "a descrição completa é ilusória. Todavia, a descrição densa é preferível, e epistemologicamente mais recompensadora, que uma descrição escassa". Outro fator importante é a amplitude, ou seja, a tentativa de "descobrir algo sobre todos os tópicos que são abarcados pela pesquisa, mesmo que tangencialmente". Assim, como demonstraremos no relato de nosso percurso metodológico e na descrição das técnicas de pesquisa empregadas, procuramos descrever e explicar nosso objeto da forma mais densa e ampla possível (Becker, 2014, pp. 193 - 194).

\section{Método de procedimento: avaliação legislativa}

O emprego da comparação entre casos exigiu, primeiramente, a coleta de dados empíricos a partir de critérios que permitiriam observar semelhanças e diferenças. Em seguida, passamos a "estudos de 
segundo nível", ou seja, à "reflexão sobre as descobertas empíricas a partir da comparação de dados e do isolamento de variáveis". A partir dessas análises, pretendemos "extrair ensinamentos e orientações" (Bucci, 2013, pp. 297 - 300) que pudessem ser úteis para o aperfeiçoamento da Emenda.

Cada um dos casos (municípios) objeto desta investigação foram estudados por meio do método de procedimento de avaliação legislativa. A "avaliação legislativa traduz-se num modelo teórico que se propõe a avaliar atos normativos sob o enfoque dos efeitos que estes produzem na sociedade". Para tanto, "os critérios de eficácia, efetividade, eficiência e impacto da legislação são utilizados para verificar se as normas atingem os objetivos para os quais foram elaboradas" (Salinas, 2008, p. 7). Algumas perguntas fundamentais norteiam as avaliações legislativas: 1) o que mudou com a edição da norma? Tratam-se das mudanças pretendidas? 2) Por que as mudanças ocorreram? Devem-se à norma ou a outros fatores? 3) As mudanças tornaram o contexto anterior à norma melhor, pior ou continuou igual? 4) Quem foi afetado pela norma? Diferentes aspectos da legislação e dos processos a ela relacionados em determinado período de tempo devem ser considerados, incluindo a adoção da norma, sua implementação e seus impactos (European Comission, 2008, p. 6).

A utilidade da avaliação legislativa consiste em fornecer elementos concretos que permitam eventuais adaptações da legislação às necessidades, além de possibilitar que todos conheçam os benefícios (ou malefícios) da adoção da norma (European Comission, 2008, p. 7).

Um dos modelos de avaliação legislativa é o de "avaliação legislativa de impacto", a qual é "destinada a descrever os efeitos produzidos por uma legislação, ainda que não correspondentes aos objetivos estabelecidos pelo legislador, e também a reconstituir as razões que provocam tais consequências inesperadas" (Salinas, 2008, p. 14).

O "estudo de impacto legislativo", que é um ramo da Legística material consiste na "apreciação pormenorizada dos projetos legislativos", considerando-se, por exemplo, questões pertinentes a seus benefícios, incentivos para alcançar seus objetivos (explícitos e implícitos) e consequências esperadas e inesperadas. Tais estudos podem ser realizados "antes ou depois da implementação da lei, com o fim de antecipar o seu impacto ou verificar sua efetividade" (Meneguin, 2010, pp. 5 - 7). 0 emprego deste método permitiu, pois, por um lado, verificar a eficácia, a efetividade, a eficiência e os impactos da Emenda nos municípios analisados; e, por outro lado, a partir dessas conclusões, antecipar o impacto da eventual aprovação da Emenda Constitucional do Programa de Metas nas três esferas da Federação brasileira. Portanto, o objetivo direto desta pesquisa foi realizar uma avaliação legislativa retrospectiva (ex post), entretanto, indiretamente, contribuirá com uma avaliação prospectiva (ex ante) no que se refere às PECs que tramitam no Congresso Nacional.

É preciso diferenciar os efeitos dos impactos de uma lei, pois os primeiros referem-se apenas às "consequências pretendidas pelo legislador", enquanto os últimos representam todas as consequências decorrentes da aplicação de uma legislação, ainda que não previstas ou pretendidas por quem a formulou". Por sua vez, os efeitos podem ser avaliados quanto à sua eficácia ("aptidão de uma determinada lei para atingir as finalidades que prescreve"), efetividade ou eficácia social ("obediência dos destinatários de uma determinada norma ao comportamento esperado pelo legislador") e eficiência ("relação entre 'custos' e 'benefícios' de uma legislação" tanto na dimensão interna (do Poder Público) como externa) - e todas essas perspectivas devem ser consideradas. Registramos que, na análise dos impactos, é preciso, "identificar se as consequências atribuídas a uma lei decorrem realmente de sua aplicação" e não de outros fatores, o que "se situará no domínio da probabilidade ou da plausibilidade, e não da certeza inerente às ciências exatas" (Salinas, 2008, pp. 37 - 41).

Ressaltamos que a norma objeto da avaliação não pode ser analisada isoladamente, mas sim em conjunto com fatores que influenciam seus efeitos e seus impactos, como o arcabouço normativo a que pertence, o contexto político em que está inserida e a variedade de formas legislativas, as diferentes maneiras de implementação da legislação e alternativas existentes por meio das quais se poderia tentar atingir os mes- 
mos objetivos efeitos positivos e negativos da legislação (European Comission, 2008, pp. 8, 11, 15, 24).

Assim, para uma adequada avaliação da Emenda consideramos: a) as normas do Ordenamento Jurídico Brasileiro relacionadas com sua temática e seu campo de incidência; b) o contexto político brasileiro e as especificidades de cada município avaliado, em especial as condições de exercício da cidadania no Brasil; c) os atores envolvidos e potencialmente afetados, especialmente agentes políticos e lideranças de movimentos sociais; d) outras formas normativas e mesmo instrumentos não jurídicos que poderiam ser utilizados para atingir os mesmos objetivos da Emenda.

\section{$7 \quad$ Técnicas empregadas na pesquisa empírica}

O sucesso da avaliação legislativa, além das perguntas corretas, depende da adequada definição sobre onde devem ser encontradas as respostas, ou seja, das fontes de informações da avaliação. Como roteiro para realização da coleta de dados (informações) elaboramos um quadro que contempla em suas colunas: (1) categoria de informação a ser obtida; (2) questão de avaliação; (3) tipo de dado a ser coletado; e (4) fonte de informação (European Comission, 2008, pp. 33 - 35).

Para coletar os dados necessários para a realização desta avaliação legislativa adotamos, basicamente, duas técnicas: a análise documental e a entrevista semiestruturada. Antes de tratarmos de cada uma dessas técnicas, julgamos necessário apresentar algumas considerações gerais sobre os procedimentos adotados na coleta de dados.

A propósito, Epstein e King (2013, pp. 47 - 56) ressaltam que a validade de uma pesquisa empírica depende da possibilidade de ser replicável, ou seja, deve fornecer todas as informações necessárias para que qualquer outro pesquisador consiga "entender, avaliar, basear-se em, e reproduzir a pesquisa". Os procedimentos da investigação devem ser tornados públicos, sobretudo porque geralmente influenciam seus resultados. Isso implica, por exemplo, em deixar claros os critérios utilizados na seleção das amostras (documentos, entrevistados), de qual população foi extraída (universo existente), todos os detalhes sobre como se teve acesso às informações (fontes dos documentos, como os entrevistados foram contatados, como ocorreram as entrevistas, quem foram os entrevistadores etc.) e as dificuldades encontradas.

Em síntese, na seleção das observações a serem incluídas na pesquisa, quatro regras fundamentais devem ser seguidas: a) identificar a população de interesse; b) coletar o máximo de dados possível; c) registrar o processo pelo qual os dados foram observados; e d) coletar dados de maneira que evite o viés de seleção" (Epstein \& King, 2013, pp. 127 - 130).

Registramos, também, as recomendações da European Comission (2008, pp. 43 - 51) sobre o procedimento de coleta de dados em uma avaliação legislativa. De acordo com esse órgão, a avaliação legislativa pode começar por uma pesquisa documental (revisão de literatura, identificação de diferentes perspectivas de análise e informações que exigem verificações complementares etc.). Em seguida inicia-se a coleta de dados, agenda-se entrevistas, etc. Com as informações obtidas, procede-se a uma análise preliminar, estabelecendo-se tipologias para a avaliação. Na coleta de informações, é preciso cuidado quando as informações apropriadas não estiverem disponíveis e for necessário utilizar alternativas. É preciso ter segurança de que todas as fontes de informações utilizadas são confiáveis e verificáveis. Para tanto, é importante que as informações sejam obtidas junto a diferentes fontes ou grupos, e que esses sejam suficientemente representativos. Enfim, os resultados encontrados devem ser devidamente analisados e validados.

A análise documental foi uma técnica indispensável para a realização desta investigação. Embora apresentem algumas limitações, os documentos são as fontes mais confiáveis de dados sobre os efeitos e impactos de uma lei.

Além dessa particularidade, a análise documental tem o mérito de ser "um método de coleta de dados que elimina, ao menos em parte, a eventualidade de qualquer influência - a ser exercida pela presença ou intervenção do pesquisador - do conjunto das interações, acontecimentos ou comportamentos pesquisados, anulando a possibilidade de reação do sujeito à operação de medida". Por outro lado, "não é menos 
verdade que o documento constitui um instrumento que o pesquisador não domina. A informação, aqui, circula em sentido único" (Cellard, 2010, p. 295).

Há algumas recomendações importantes a serem seguidas em uma análise documental: a) é preciso verificar a pertinência dos documentos ao objeto da pesquisa, sua credibilidade, autenticidade, confiabilidade e representatividade no que se refere aos dados que fornece do universo pesquisado; b) a boa análise e interpretação de qualquer documento pressupõe o "exame do contexto social global" em que foi editado (“conjuntura política, econômica, social e cultural”); c) também é fundamental ter algum conhecimento sobre a "identidade da pessoa que se expressa, de seus interesses e dos motivos que a levaram a escrever"; d) enfim, "é a qualidade da informação, a diversidade das fontes utilizadas, das corroborações, das intersecções, que dão sua profundidade, sua riqueza e seu refinamento a uma análise” (Cellard, 2010, pp. 296 - 305).

Considerando-se essas premissas, analisamos os seguintes documentos: a) normas federais pertinentes e decisões judiciais; b) Emendas às Leis Orgânicas do Programa de Metas (de todos os municípios em que foram aprovadas); c) documentos referentes à tramitação nas Câmara Municipais dos projetos que resultaram nas Emendas às Leis Orgânicas do Programa de Metas; d) outros dispositivos pertinentes das Leis Orgânicas dos municípios estudados; e) notícias e artigos publicados na imprensa local sobre o tema; f) programas de governo protocolizados junto à Justiça Eleitoral no momento do registro das candidaturas dos Prefeitos eleitos em 2012; g) Programas de Metas apresentados pelos Prefeitos eleitos após a sua posse; h) publicações no Jornal Oficial, nos portais das Prefeituras e das Câmaras Municipais e da imprensa locais destinadas à divulgação do Programa de Metas; i) publicações de convites para audiências públicas; j) atas das audiências públicas destinadas a debater o Programa de Metas; k) publicações oficiais referentes às prestações de contas sobre o cumprimento das metas; l) publicações oficiais referentes a eventuais alterações nas metas; $m$ ) Leis do Plano Plurianual (2014/2017), de Diretrizes Orçamentárias (2013, 2014 e 2015) e Orçamentária Anual (2013, 2014 e 2015); n) informações sobre o Programa de Metas divulgados por meios não escritos (vídeos, áudios); o) informações gerais sobre o Município (obtidas junto ao IBGE e portais da Prefeitura e da Câmara Municipal). p) pareceres do Tribunal de Contas do Estado de São Paulo sobre as contas da Prefeitura Municipal referentes ao exercício de 2013 (únicos disponíveis até o momento).

Como já anotamos, os documentos são fontes de informações imprescindíveis para avaliar os efeitos e os impactos de uma lei, mas não são suficientes, sobretudo para aferirmos o que os explicam.

Assim, recorremos também à técnica da entrevista, por entendermos que é a mais adequada para o aprofundamento do conhecimento sobre o objeto da investigação - sobretudo para aferir com profundidade a percepção de atores sociais que interferem (ou podem interferir) diretamente nos resultados e impactos da Emenda. Além disso, abre-se a possibilidade de aprendizado com outras formas de saberes, particularmente daqueles produzidos pelos movimentos sociais engajados na elaboração e aplicação da Emenda e gestores públicos.

Manzini (1991, p. 150) estabelece uma relação de dependência entre a viabilidade da utilização da entrevista como técnica de coleta de dados e a natureza das informações pesquisadas. A entrevista objetiva captar aquelas informações que não estão disponíveis em meio físico, como documentos por exemplo, e sim aquelas que as pessoas guardam em suas memórias e pensamentos.

A entrevista deve preencher os seguintes requisitos: a) validade ("comparação com fonte externa, com a de outro entrevistado, observando as dúvidas, incertezas e hesitações demonstradas pelo entrevistado"); b) relevância ("importância em relação aos objetivos da pesquisa"); c) especificidade e clareza ("referência a dados, datas, nomes, lugares, quantidade, percentagens, prazos etc. com objetividade"); d) profundidade ("está relacionada com os sentimentos, pensamentos e lembranças do entrevistado, sua intensidade e intimidade"); e) extensão ("amplitude da resposta") (Marconi \& Lakatos, 2003, pp. 200 - 201). Além disso, é fundamental assegurar aos entrevistados que ninguém saberá o que disseram nas entrevistas para a validade dos resultados (Becker, 2014, p. 192). 
Há dois tipos básicos de entrevista: a padronizada ou estruturada; e a despadronizada ou desestruturada (Marconi \& Lakatos, 2003, p. 197). Há, ainda, um tipo intermediário: a semiestruturada.

Os roteiros de nossas entrevistas seguiram as recomendações apresentadas acima e foram elaborados com base nos textos sobre avaliação de políticas públicas, especialmente da avaliação de implementação de Draibe (2001), e da elaboração de entrevistas semiestruturadas na pesquisa social de Manzini (1991). A elaboração do roteiro também utilizou o modelo teórico proposto por Draibe (2001), por referir-se especificamente à avaliação da implementação de uma política pública. A autora apresenta um esboço metodológico, com base na sua experiência como avaliadora de políticas e programas sociais, no qual ela identifica os subprocessos ou sistemas de implementação, que denomina como "anatomia do processo geral de implementação".

Assim, a partir de roteiros previamente estabelecidos, mas flexíveis, selecionamos para serem entrevistados, em cada município estudado, um conjunto de atores que representam, por um lado, aqueles que são responsáveis pela aplicação da Emenda (Poder Executivo e Poder Legislativo) e, por outro, pela fiscalização e mobilização por sua aplicação (sociedade civil, imprensa e também o Poder Legislativo). Especificamente, foram relacionados os seguintes potenciais entrevistados: a) gestor público responsável pela coordenação da gestão do Programa de Metas; b) representantes do Poder Legislativo municipal; c) representantes de movimentos semelhantes à RNSP ou, quando não há, de outras organizações da sociedade civil que tenham participado da mobilização pela aprovação e aplicação da Emenda do Programa de Metas; ou, ainda conselheiros municipais de políticas públicas; e) editores de política de órgãos da imprensa local. Procuramos, pois, pesquisar qualitativamente a percepção dos principais atores envolvidos com a Emenda a propósito de sua aplicação.

\section{Percurso e dificuldades metodológicos}

É necessário estabelecer uma conexão da pesquisa desenvolvida com o conhecimento já produzido, analisando-se a literatura acadêmica relevante. Isso é fundamental pois: confere mais credibilidade à pesquisa; ajuda a evitar erros; permite "pular árduas reinvenções de ideias já existentes"; "diminui as chances de se fazer novamente um trabalho já feito"; possibilita que se considere as "lições dos estudos anteriores" sobre o mesmo problema; e indica que há outros interessados no assunto (Epstein \& King, 2013, pp. 71 - 78). Por essas razões, procuramos fazer uma ampla revisão bibliográfica sobre o modelo de democracia participativa, o experimentalismo democrático e experimentos de democracia participativa.

Em seguida, analisamos as condições histórico-sociais do exercício da cidadania no Brasil. Isso porque, uma norma não é abstratamente aplicada, mas sempre em uma realidade concreta, notadamente quando sua pretensão é o aperfeiçoamento do processo político-democrático. Assim, com caráter introdutório e utilizando algumas das principais interpretações sobre a formação do Estado brasileiro e o contexto político nacional contemporâneo, estabelecemos algumas referências para melhor compreensão das informações obtidas empiricamente a fim de conhecer as razões do descumprimento ou do cumprimento (em diferentes graus) da Emenda.

A terceira parte da pesquisa consistiu na sistematização e no aprofundamento da análise das informações obtidas na pesquisa exploratória realizada para a preparação do projeto, por meio da técnica do mapeamento legislativo, o qual compreendeu um panorama histórico-legislativo da Emenda que abrangeu: a) a iniciativa da sociedade civil, a aprovação da Emenda à Lei Orgânica e o primeiro Programa de Metas do Município de São Paulo; b) a aprovação da Emenda do Programa de Metas em outros municípios brasileiros e da América do Sul; c) os Projetos de Emenda à Constituição Federal que pretendem instituir a obrigatoriedade de elaboração do Programa de Metas para Prefeitos, Governadores e Presidente da República; d) as ações diretas de inconstitucionalidade propostas contra as Emendas às Leis Orgânicas que instituíram o Programa de Metas; e) a análise comparativa dos textos das Emendas às Leis Orgânicas que instituíram a obrigatoriedade do Programa de Metas; f) o confronto da Emenda com outros dispositivos normativos do Ordenamento Jurídico brasileiro que tratam de participação popular, controle social e pla- 
nejamento na Administração Pública; g) a revisão da produção acadêmica sobre o tema.

A partir dos referenciais teóricos revisados e dos resultados preliminares obtidos com o mapeamento legislativo, passamos propriamente à avaliação legislativa, dividida em duas partes: a) coleta e análise dos documentos; b) seleção de entrevistados, agendamento e realização de entrevistas, e sistematização das informações obtidas.

Como ressaltam Epstein e King (2013, p. 23), uma pesquisa empírica de qualidade deve apresentar um dos seguintes objetivos ou a combinação dos três: "coletar dados para uso do pesquisador ou de outros; resumir dados para que sejam facilmente compreendidos; e fazer inferências descritivas ou causais, o que envolve usar os dados que observamos para aprender sobre os dados que queremos levantar". Além disso, é necessário que sejam seguidas determinadas regras para alcançar tais objetivos.

Esta pesquisa cumpre um primeiro objetivo científico de coletar, organizar e disponibilizar dados que possam ser consultados por outros pesquisadores, no que se refere à edição e aplicação da Emenda dentro do recorte espacial estabelecido - ou seja, a criação de um banco de dados. Tais dados, que se encontram dispersos em diferentes fontes e localidades compreendem documentos (leis, relatórios, atas, notícias etc.) e impressões dos atores envolvidos na aplicação da norma. Assim, recolher, organizar esses dados e disponibilizá-los em uma única plataforma foi a primeira tarefa desta investigação, sendo pressuposto para o desenvolvimento das etapas subsequentes, bem como útil para outros pesquisadores que queiram se dedicar ao mesmo objeto.

Tendo em vista a validade científica da coleta e organização desses dados (Epstein \& King, 2013, p. 28); tivemos a preocupação de registrar: a) a origem e a data da coleta de todos os documentos obtidos na internet; b) a repartição pública, a data da coleta e o responsável pela entrega de todos os documentos obtidos presencialmente; c) a qualificação dos entrevistados, o local e a data das entrevistas, e, sempre que possível, o conteúdo integral da entrevista gravado em áudio.
A segunda tarefa consistiu em resumir os dados obtidos, pois respostas descritivas às questões formuladas para a investigação exigem que se faça isso. Além disso, não é possível que qualquer ser humano armazene em sua mente as informações disponíveis no banco de dados, e muitos não conseguiriam compreendê-las (Epstein \& King, 2013, pp. 29 - 35).

Assim, o segundo esforço da parte empírica desta pesquisa consistiu em selecionar, codificar e tabular, enfim, resumir os dados coletados (descrever as informações obtidas), tanto em termos numéricos como verbais. Isso compreendeu a sistematização das informações obtidas em cada um dos municípios investigados que adotou a Emenda - o que resultou em relatórios de cada caso estudado elaborados a partir de formulários padronizados - e o estabelecimento de comparações entre eles, o que gerou estatísticas sobre o cumprimento (total ou parcial) ou descumprimento de cada preceito que compõe a referida norma, bem como sobre fatores presentes ou ausentes em cada localidade que ajudam a explicar seus diferentes graus de êxito. Entretanto, a análise quantitativa foi insuficiente para fornecer as informações necessárias para esclarecer as questões que envolvem esta investigação. Dessa maneira, elaboramos resumos verbais das informações qualitativas obtidas tanto por meio das entrevistas semiestruturadas como dos documentos analisados. Realizamos, ainda, uma confrontação entre as informações obtidas por meio dos documentos e das entrevistas.

Passamos, então, à análise e interpretação dos resultados, ocasião em que procuramos responder, de forma sistemática e articulada, às questões que nortearam a pesquisa e desenvolver inferências

A inferência pode ser definida como "o processo de utilizar fatos que conhecemos para aprender sobre fatos que desconhecemos". As inferências podem ser descritivas ou causais. As inferências descritivas consistem em, por meio da coleta de observações de um caso determinado "em um ponto específico de tempo", tentar "aprender algo" sobre a localidade estudada de maneira geral (e não somente no intervalo temporal observado), bem como obter generalizações sobre um campo geográfico amplo baseadas em "testes em uma pequena parte dele" (amostra). 
Ou seja, trata-se de aprender algo sobre períodos de tempo e espaços não observados na realização da pesquisa. Entretanto, alguns cuidados são necessários. (Epstein \& King, 2013, pp. 36 - 42).

Dessa forma, a aplicação da inferência descritiva ao objeto desta pesquisa consistiu em saber, por exemplo, se as conclusões obtidas em relação aos municípios observados podem ser generalizadas para outros não estudados, bem como se as conclusões específicas sobre a Emenda podem ser generalizadas para outras experiências de inovação institucional no campo da democracia participativa. Ou seja, tratou-se de aprender sobre o restante dos municípios brasileiros que adotaram a Emenda e sobre as inovações institucionais na democracia participativa em geral a partir dos resumos de dados específicos.

Já as inferências causais se referem à tentativa de "saber se um fator ou conjuntos de fatores leva a (ou causa) algum resultado". Mais precisamente, trata-se de se saber se eventos específicos ("variável causal principal”) "'causaram' um resultado específico, ou variável dependente". Ressaltamos que "os possíveis eventos e resultados podem ser caracterizados como variáveis que assumem diferentes valores, isto é, elas variam" - o evento existe ou não; a partir da ocorrência do evento, a variável dependente pode aumentar, diminuir ou permanecer igual. Para fazer essa constatação, observamos "o que ocorre antes e após uma mudança na variável causal”. Para que fosse possível verificar com precisão se determinado evento foi o fator determinante de certo resultado, seria necessário "reviver a história" sem a ocorrência do evento (ou "tratamento" sobre a realidade previamente existente) e aferir a ocorrência ou não do resultado. Entretanto, isso não é possível, de maneira que é necessário o recurso à inferência causal, "que também está relacionada ao uso de fatos conhecidos para aprender sobre fatos desconhecidos". Para tanto, a existência de um "controle", ou seja, a observação de um contexto análogo em que o evento analisado não ocorreu e em que os demais fatores são idênticos é fundamental.

Assim, "uma inferência causal é a diferença entre duas inferências descritivas" - a da situação em que foi aplicado o "tratamento" e a em que se aplicou o "controle". Entretanto, há uma dificuldade, conheci- da como "problema fundamental da inferência causal": só é possível estimar diretamente determinado resultado ou quando o "tratamento" ou quando o "controle" é aplicado - não é possível fazê-lo para ambos. Assim, "nunca será possível fazer inferências causais com certeza", de maneira que "no máximo, uma das inferências descritivas será baseada em informação 'factual', e no mínimo uma demandará inferência 'contrafactual'”. Trata-se, pois, de um problema sem solução, mas que pode ser minimizado por meio de: a) precisão das questões formuladas; b) utilização das técnicas adequadas para redução das incertezas e viesses; c) "comunicar o nível apropriado de incerteza que os leitores devem ter ao interpretar seus resultados" (Epstein \& King, 2013, pp. 43 - 46).

Em torno das inferências causais encontram-se as questões fundamentais desta pesquisa: a edição da Emenda provocou um aperfeiçoamento do controle social das políticas públicas e um aprofundamento da democracia participativa? Quais fatores explicam (causaram) o êxito ou o fracasso (total ou parcial) dos objetivos pretendidos pela norma em diferentes municípios observados? Como não é possível "reviver a história" desses municípios, ou seja, saber como se passaria o processo político no que se refere aos objetivos pretendidos pela Emenda sem que ela tivesse sido adotada, recorremos a um "controle", qual seja: a observação de dois municípios em que a Emenda não foi editada mas em que há movimentos sociais organizados em defesa de objetivos semelhantes aos que são almejados por elas. Com isso, procuramos inferir quais resultados e impactos decorreram efetivamente da edição da norma, ou seja, desenvolver a avaliação legislativa.

Há nessas questões dificuldades adicionais. A primeira delas em relação a análises cujos parâmetros não podem ser quantificados: os critérios contidos nas perguntas desta investigação apresentam considerável conteúdo axiológico e sua definição apresenta até mesmo certa arbitrariedade - o que caracteriza o controle social das políticas públicas como melhor ou pior? Maior número de participantes ou de pessoas que conhecem os processos político-decisórios seria um critério suficiente para definir isso? Parece-nos que não. Analisar um objeto de natureza política que envolve não apenas questões de legalidade/ 
efetividade, mas sobretudo de legitimidade, a partir de técnicas e procedimentos metodológicos empíricos constituiu pois, uma atividade complexa, e os resultados da investigação devem ser ponderados considerando-se esse parâmetro.

Em segundo lugar, no que se refere ao "controle", não é possível saber com precisão que, exceto a existência da Emenda, os demais fatores relevantes são idênticos nos dois municípios observados com tal propósito, pois há particularidades políticas, sociais, econômicas e culturais extremamente complexas que podem influenciar nos resultados observados. Além disso, os municípios selecionados para realizar o controle (Piracicaba e Mogi das Cruzes) permitem uma comparação com municípios em que há movimentos sociais organizados e a Emenda à Lei Orgânica (São Paulo, por exemplo), mas não exatamente com um terceiro tipo de município incluído no universo da pesquisa (mais comuns do que inicialmente esperávamos): aqueles em que há a Emenda mas não existe movimento organizado que tenha no seu campo de ação a fiscalização da aplicação da Emenda. Ponderamos, ainda, a existência de grande variação de grau de organização e capacidade de articulação e influência de diferentes movimentos envolvidos com o tema.

Em termos operacionais, a primeira dificuldade encontrada foi o acesso a determinados documentos que, em tese, considerando-se o disposto nas Leis da Transparência e de Acesso à Informação, deveriam ser facilmente acessíveis. Entretanto, em alguns municípios não se encontravam nos portais das Prefeituras e Câmara Municipais e, não obstante o envio de três solicitações por e-mail para os servidores públicos que deveriam ser responsáveis por sua disponibilização, não conseguimos obtê-los até a conclusão da pesquisa.

A mesma dificuldade se reproduziu com relação ao agendamento de entrevistas, visto que alguns agentes públicos não se interessaram por colaborar com nossa investigação e outros que colaboraram, embora em tese deveriam dominar o assunto, na verdade revelaram grande desconhecimento sobre as determinações e a aplicação da Emenda - o que, todavia, representou um resultado de pesquisa: um fator indicativo da inefetividade da norma avaliada.
No campo da sociedade civil, também encontramos organizações que acompanham a aplicação da Emenda em poucos municípios, o que dificultou a análise sobre a percepção da sociedade a propósito da efetividade da norma a partir da técnica e do recorte escolhidos. Nesse sentido, notamos que para uma avaliação mais aprofundada da qualidade do controle social das políticas públicas a análise documental e as entrevistas revelaram-se como técnicas insuficientes, demandando-se estratégias que permitam um contato maior com os atores sociais que se engajam nos espaços participativos e uma observação mais intensa dos processos, como a metodologia da observação participante.

Compuseram, ainda, esta pesquisa, algumas reflexões sobre suas questões de base, já mencionadas anteriormente, e as implicações teóricas dos resultados da pesquisa empírica - o que, registra-se, não constituiu nosso objeto principal. Por fim, a última parte do trabalho - na qual o enfoque da Teoria do Estado na projeção de instituições manifestou-se de forma mais intensa - compreendeu a apresentação de algumas propostas de alteração legislativa, fundamentadas no diagnóstico realizado, no modelo de democracia participativa e no "experimentalismo democrático". As conclusões obtidas a partir de metodologia empírica contribuíram com a elaboração de propostas mais consistentes e melhor fundamentadas que, embora não sejam politicamente neutras, apresentam um ganho de objetividade que não teríamos se fossem baseadas fundamentalmente em reflexões abstratas.

\section{Conclusão}

Este artigo, como registrado inicialmente, insere-se em um conjunto de reflexões sobre os sentidos contemporâneos da Teoria do Estado e constitui o capítulo metodológico da pesquisa "Inovação institucional e democracia participativa: avaliação legislativa da Emenda do Programa de Metas".

Para tanto, inicialmente apresentamos uma compreensão de Teoria do Estado que almeja a produção de um conhecimento realista e transformador, de caráter discursivo, mas também empírico, sem abandonar sua fundamental dimensão normativa e sem confundir 
objetividade com neutralidade. Em seguida, tratamos das implicações mútuas entre teoria e empiria, aplicando-as ao nosso objeto de investigação. Em terceiro lugar, descrevemos a delimitação de nosso problema com seus diferentes planos analíticos, demonstrando como para cada um deles o recurso a formulação de hipóteses de pesquisa e a determinação das variáveis a serem medidas e relacionadas revela-se ou não adequado. Na quarta parte do trabalho tratamos dos métodos de abordagem empregados, os quais também variaram conforme o plano analítico da investigação e, em seguida, descrevemos nosso método de procedimento (avaliação legislativa) e sua aplicação sobre nosso objeto. Na sexta parte do trabalho tratamos das técnicas que empregamos (análise documental e entrevistas semiestruturadas) e suas limitações.

Enfim, apresentamos nosso percurso e as dificuldades metodológicas enfrentadas, notadamente no que se refere à busca de objetividade e do rigor na aplicação de técnicas empíricas à análise de um objeto de natureza política, cujas questões de legitimidade têm especial relevância, além dos obstáculos operacionais na obtenção de informações junto a repartições e agentes públicos. No que se refere às técnicas de pesquisa, observamos também que um conhecimento mais aprofundado sobre a qualidade do controle social não pode ser obtido apenas por meio de documentos e entrevistas, podendo contribuir para tanto, por exemplo, a observação participante.

Concluímos que é possível e vantajosa a utilização de métodos empíricos pela Teoria do Estado no conhecimento sobre a democracia se a disciplina pretender adotar como enfoque a projeção de instituições fundada na realidade - ainda que não se trate de uma tarefa politicamente neutra. Isso conferirá maior objetividade, densidade e aplicabilidade aos resultados das pesquisas desenvolvidas neste campo do conhecimento do que se ficasse restrita às ferramentas exclusivamente teóricas. Entretanto, os resultados de pesquisas como a que desenvolvemos devem ser ponderados considerando-se as peculiaridades dos objeto e do enfoque da Teoria do Estado, pois abrange questões de legitimidade política em cujas análises o interesse e a ideologia serão elementos sempre presentes.

\section{Referências}

Bauböck, R. (2008). Normative political theory and empirical research. In: Della Porta, D., Keating, M. (ed.). Approaches and methodologies in the social sciences: A pluralist perspective (pp. 40 -60). Cambridge: Cambridge University.

Becker, H. S. (2014). A Epistemologia da Pesquisa Qualitativa. Trad. J. G. Paixão. Revista de Estudos Empíricos em Direito, 1(2), 184 - 198.

Bobbio, N. (1992). Ciência Política. In: N. Bobbio, N. Matteucci, G. Pasquino (Org.), Dicionário de Política (pp. 164 - 169). Trad. C. C. Varriale et alli. V. 1. $7^{\text {a }}$ ed. Brasília: UNB.

(2000). Teoria Geral da Política - A Filosofia Política e as Lições dos Clássicos. Org. Michelangelo Bovero. Trad. Daniela Beccaccia Versiani. Rio de Janeiro: Elsevier, 2000.

Bonavides, P. (1995). Ciência Política. 10ª ed. São Paulo: Malheiros.

Bucci, M. P. D. (2013). Fundamentos para uma Teoria Jurídica das Políticas Públicas. São Paulo: Saraiva.

Caupers, J. (2003). Relatório sobre o programa, conteúdo e método de uma disciplina de Metódica da Legislação. Cadernos de Ciência da Legislação, 35, 5 - 87.

Cellard, A. (2010). A análise documental. In: J. Poupart et alli (Org.), A pesquisa qualitativa: enfoques epistemológicos e metodológicos (pp. 295 - 316). Trad. A. C. Nasser. $2^{a}$ ed. Petrópolis: Vozes.

Dallari, D. A. (2010). Elementos de Teoria Geral do Estado. São Paulo: Saraiva.

Deslauriers, J. P., Kérsit, M. (2010). O delineamento de pesquisa qualitativa. In: J. Poupart et alli (Org.), A pesquisa qualitativa: enfoques epistemológicos e metodológicos (pp. 127 - 153). Trad. A. C. Nasser. $2^{a}$ ed. Petrópolis: Vozes.

Draibe, S. M. (2001). Avaliação de Implementação: Esboço de uma Metodologia de Trabalho em Políticas Públicas. In: M. C. R. N. Barreira, M. C. B. CARVALHO, (Org.), Tendências e Perspectiva na Avaliação de Políticas e Programas Sociais. São Paulo: IEE/PUC/SP 2001.

Epstein, L., King, G. (2013). Pesquisa Empírica em Direito: as Regras de Inferência. Trad. Fábio Morosini (coord.) et alli. São Paulo: Direito GV.

European Comission (2008). DG Market Guide to Evaluating Legislation. Brussels. Recuperado em 09 de abril de 2015 de: <http://ec.europa.eu/dgs/internal_market/docs/evaluation/evaluation_guide.pdf>. 
Ferraz Jr., T. S. (1980). A Ciência do Direito. $2^{a}$ ed. São Paulo: Atlas.

Gil, A. C. (2008). Métodos e Técnicas de Pesquisa Social. $6^{a}$ ed.. São Paulo: Atlas.

Horta, Ricardo L., Almeida, V. R., Chilvarquer, M. (2014). Avaliando o Desenvolvimento da Pesquisa Empírica em Direito: o caso do projeto pensando o direito. Revista de Estudos Empíricos em Direito, 1 (2), 162 - 183.

Manzini, E. J. (1990/1991). A Entrevista na Pesquisa Social. Didática, 26/27, 149 - 158.

Marconi, M. A., Lakatos, E. M. (2003). Fundamentos de Metodologia Científica. $5^{a}$ ed. São Paulo: Atlas.

Marsh, D., Furlong, P. (2002). A skin not a sweater: Ontology and epistemology in political science. In: Marsh, D., Stoker, G.. Theory and methods in political science (pp. 17 -41). London: Pallgrave McMillan.

Meneguin, F. B. (2010). Avaliação de Impacto Legislativo no Brasil. Textos para Discussão do Centro de Estudos da Consultoria do Senado, n. 70.

Popper, K. R. (2008). A Lógica da Pesquisa Científica. $16^{\mathrm{a}}$ ed. Trad. Leonidas Hegemberg e Octanny Silveira da Mota. São Paulo: Cultrix.

Salinas, N. S. C. (2008). Avaliação Legislativa no Brasil: um estudo de caso sobre as normas de controle das transferências voluntárias de recursos públicos para entidades do terceiro setor. Tese (Mestrado em Filosofia e Teoria Geral do Direito) - Faculdade de Direito da Universidade de São Paulo, São Paulo.

Salomão Filho, C. (1999). Globalização e Teoria Jurídica do Conhecimento Econômico. In: C. A. Sundfeld, O. V. Vieira (Org.), Direito Global. São Paulo: Max Limonad.

Santos, B. S. (2011 - 2012). Introducción: las Epistemologías del Sur. In: CIDOB (Org.), Formas-Otras. Saber, nombrar, narrar, hacer (pp. 9 - 22). Barcelona: CIDOB. Recuperado em 30 de julho de 2014 de: <http://www.boaventuradesousasantos.pt/ media/INTRODUCCION_BSS.pdf>. (2001). Seis Razões para Pensar. Lua Nova, 54, $13-23$.

(1988). Um discurso sobre as Ciências na transição para uma ciência pós-moderna. Estudos Avançados, 2(2), 46 - 71.

Sartori, G. (1981). A Política. Trad. Sérgio Bath. Brasília: UnB.
Tojal, S. B. B. (1997). Teoria Geral do Estado - Elementos de uma Nova Ciência Social. Rio de Janeiro: Forense.

Unger, R. M. (1996). What Should Legal Analysis Become? London/New York: Verso.

Valverde, M. (2016). What counts as theory, today? - A post-philosophical framework for social-legal empirical research. Revista de Estudos Empíricos em Direito, 3(1), 172 - 181.

Data de submissão/Submission date: 11.01.2017.

Data de aceitação para publicação/Acceptance date: 24.07.2018. 